\title{
PERFIL PSICOSSOCIAL DAS PESSOAS AGREDIDAS POR ANIMAIS RAIVOSOS OU SUSPEITOS DE RAIVA NA GRANDE SÃO PAULO
}

\author{
Mara Cleide Dias Ramos*
}

\begin{tabular}{l|l|} 
RSPUB9/391 \\
\hline
\end{tabular}

Ramos, M. C. D. Perfil psicossacial das pessoas agredidas por animais raivosos ou suspeitos de raiva na Grande Sáo Paulo, Rev. Saúde públ., S. Paulo, 12: 26-34, 1978.

RESUMO: Foi determinado o perfil psicossocial das pessoas agredidas por animais raivosos ou suspeitos de raiva na Grande Sáo Paulo através das caracteristicas da clientela atendida pelo Instituto Pasteutr de São Paulo, Brasil. Conclutultse que esta população procede das periferias da Capital e dos municipios limitrofes; o nivel sócio-econômico é baixo; uma parcela considerável corre o risco de se contaminar em sua própria residência; $e$, a maioria desconhece os reais riscos da doença. Portanto, os programas educativos devem ser intensificados e adaptados às peculiaridades da população sob risco de contrair a raiva.

Unitermos: Raiva, aspectos psicossociais. Raiva, Säo Paulo, Brasil. Educação sanitária.

\section{INTRODUÇÃO}

As investigações sobre a raiva hilmana em São Paulo tem enfocado, basicamente, o tratamento preventivo pela vacinação do individuo submetido ao risco do contágio $1,2,3,4,5,4,7,8$.

O conhecimento dos aspectos epidemiclógicos e psicossociais das pessoas agredidas por animais raivosos ou suspeitos de raiva permitirá o planejamento de programas educacionais, os quais, postos em prática, poderão reduzir ao mínimo a exposição humana a esta infecção em São Paulo.

Neste sentido, o estudo de Ribeiro Neto é uma contribuiçăo importante à abordagem dos aspectos epidemiológicos, enquanto () de Tiriba ${ }^{11}$ levanta alguns aspectos sociais que envolvem o homem afetado pela raiva, sem caracterizar aquele que se encontra sob o risco.

O presente trabalho visa determinar os aspectos psicossociais das pessoas agredidas por animais raivosos ou suspeitos de raiva na Grande São Paulo. Para tanto, foi escolhida a clientela do Instituto Pasteur de São Paulo, cujo campo funcional abrange :

a) supervisão, coordenação ex execuçào de atividades de profilaxia ou prevenção da raiva humana no Estado de São Paulo;

b) realização de: exame e tratamento das pessoas possivelmente contaminadas por mordeduras ou arranhaduras produzidas por cães ou outros animais capazes de transmitir a raiva; provas relativas ao

* Do Instituto Pasteur da Secretaria de Estado da Saúdo - Ay. Páulista, 393 - São Paulo. SP - Brasil. 
RAMOS. M. C, D. Perfil psicossocial das pessoas agredidas por animais raivosos ou suspeitos de raiva na Grande São Paulo. Rev. Saúde públ., S. Paulo, 12:26-34, 1978.

diagnóstico da raiva no homem e nos animais; controle biológico e químico dos produtos utilizados no Instituto;

c) desenvolvimento de planos de pesquisas relacionados com o diagnóstico e profilaxia da raiva humana;

d) organização de cursos relativos ao controle da raiva humana;

e) colaboração com o ensino das Escolas Médicas na área de sua competência.

Sendo o Instituto o órgão de atuação na Grande São Paulo, nessa especialidade, pode-se deduzir que a caracterização da clientela corresponde ao perfil psicossocial típico das pessoas agredidas por animais raivosos ou suspeitos de raiva nesta área.

Este trabalho vem ao encontro a uma das recomendações do I Seminário sobre Técnicas de Controle da Raivay, o qual propõe que se realize diagnóstico da situação através de pesquisas junto à população em geral e a grupos da comunidade, com relação ao problema da raiva.

\section{METODOLOGIA}

O total de casos estudados foi de 1.177 clientes atendidos pelo Serviço Social do Institutor Pasteur, no pós consulta médica, entre agosto e novembro de 1976, no horário de 8 às 14 horas. Este número corresponde a $24 \%$ dos pacientes submetidos a tratamento preventivo (4867), na mesma época, no horário das 8 às 22 horas.

Os 1.177 clientes foram entrevistados por meio de questionários contendo dados relativos à identificação, ocupação, tipo de proteção da residência, procedência e zona da ciclade onde reside, nível sócio-econômico e grau de conhecimento sobre a doença. Foram também observados o nivel de compreensão e o grau de ansiedade face aos riscos da doença.

Para avaliação do nivel sócio-econômico foi feita uma classificação utilizando a renda per capita mensal da clientela. Para tanto, sumou-se o salário dos membros da familia, do total diminuiu-se as despesas fixas, como aluguel, prestação de casa ou terreno e outros, e dividiu-se pelo número de membros da família. A classificação estabelecida foi :

Nivel baixo-baixo: de $\operatorname{Cr} \$ 130,00$ a menos de Cr $\$ 500,00$ mensal por pessoa.

Nível baixo-médio: de $\operatorname{Cr} \$ 500,00$ a menos de Cr\$ 1.000,00 mensal por pessoa.

Nivel baixo-alto: de $\operatorname{Cr} \$ 1.000,00$ a menos de $\operatorname{Cr} \$ 2.000,00$ mensal por pessoa.

Nivel médio-baixo: de $\operatorname{Cr} \$ 2.000,00$ a menos de $\operatorname{Cr} \$ 5.000,00$ mensal por pessua.

Nível médio-médio: de $\mathrm{Cr} \$ 5.000,00$ a menos de Cr\$ 10.000,00 mensal por pessoa.

Nível médio-alto: mais de $\mathrm{Cr} \$ 10.000,00$ por pessoa.

Para medir o grau de conhecimento da clientela sobre a doença foi feita a seguinte classificação:

- Insuficiente: Tem conhecimentos mínimos sobre a doença.

Acredita que doença provoque "loucura".

- Regular: Conhece os riscos da doença.

- Bom: Conhece os riscos, período de incubação, agente infeccioso, modo de transmissão, medidas preventivas.

Quanto ao nivel de compreensão da clientela, com relação às orientações fornecidas pelo Serviço Social do Instituto Pasteur foram:

- Insuficiente: cliente que não compreende as orientações dadas.

- Regular: cliente que compreende, usando o bom senso.

- Bom: cliente que compreende, usando o espírito crítico.

\section{RESULTADOS E COMENTARIOS}

Pode-se observar na Tabela 1 que $57,4 \%$ dos clientes do Instituto Pasteur são do sexo 
RAMOS, M. C. D. Perfil psicossocial das pessoas agredidas por animais raivosos ou suspeitos de raiva na Grande São Paulo, Rer. Saúde pribl, S. Paulo, 12.26-34, 1978.

masculino. A investigação de Ribeiro Neto ${ }^{\top}$, a qual atingiu o total de pessoas atendidas pelo Instituto en 12 meses, confirma este dado.

TA B E A 1

Clientela atendida pelo Serriço Social do Instituto Pasteur, segundo o sexo.

\begin{tabular}{lcc}
\hline Sexo & N! & $\%$ \\
\hline Masc. & 670 & 57,4 \\
Fem. & 507 & 42,6 \\
\hline Total & 1.177 & 100,0 \\
\hline
\end{tabular}

A grande maioria da clientela atendida $(73 \%$ ) é solteira. (Tabela 2) e $83,9 \%$ é de cor branca (Tabela 3 ).

T A B E A 2

Clientela atendida pelo Serviço Social do Inst1tuto Pasteur, segundo o estado civil

\begin{tabular}{lrr}
\hline Estado Civil & \multicolumn{1}{c}{ No } & \multicolumn{1}{c}{$\%$} \\
\hline Solteiro & 860 & 73,0 \\
Casado & 263 & 22,3 \\
Viúvo & 37 & 3,2 \\
Desquitado & 17 & 1,5 \\
\hline Total & 1.177 & 100,0 \\
\hline
\end{tabular}

T A B E L A

Clientela atendida pelo Serviço Social do Instituto Pasteur, segundo a cor.

\begin{tabular}{lrr}
\hline Cor & No & $\%$ \\
\hline Branco & 988 & 83,9 \\
Pardo & 99 & 8,4 \\
Preto & 68 & 5,6 \\
Amarelo & 22 & 2,1 \\
\hline Total & 1.177 & 100,0 \\
\hline
\end{tabular}

$\mathrm{Na}$ Tabela 4 pode-se verificar que mais da metade da clientela $(63 \%)$ encontra-se na faixa etária entre 0 e 20 anos, sendo que os grupos mais significativos são de menos de 7 anos $(24,8 \%)$ e de 7 a 13 anos
$(23,9 \%)$; entretanto, $50,5 \%$ da população atingida por animal com suspeita de raiva on raivoso encontra-se em uma faixa etária teoricamente produtiva, isto é, entre 14 e 70 anos. Levanta-se a hipótese de que ao mobilizar-se para o trabalho, essa população estaria mais exposta ao risco de contágio através de mordedura ou arranhaduras por cães ou outros animais de rua.

T A B E L A 4

Clientela atendida pelo Serviço Social do Instituto Pasteur. segundo a idada

\begin{tabular}{lrc}
\hline Idade & $\mathrm{N}^{\prime}$ & $\%$ \\
\hline & 293 & 24,8 \\
de 7 a 13 anos & 282 & 23,9 \\
de 14 a 20 anos & 167 & 14,3 \\
\hline Sub-total & 742 & 63,0 \\
\hline 21 a 30 anos & 169 & 14,3 \\
31 a 40 anos & 106 & 9,0 \\
41 a 50 anos & 81 & 6,7 \\
51 a 60 anos & 44 & 3,9 \\
61 a 70 anos & 26 & 2,3 \\
+ de 71 anos & 09 & 0,8 \\
\hline Total & 1,177 & 100,0 \\
\hline
\end{tabular}

A Tabela 5, sobre ocupaçoes, salienta que $30,0 \%$ dos pacientes não possuem ocupação; a grande maioria destes $(26,4 \%)$ é menor de 13 anos e não estão estudando, o que póe em relevo que o referido grupo nāo será atingido por um programa educativo junto às escolas. Entretanto, 26,1\% poderão se beneficiar com tal programa nas escolas, uma vez que a maioria são estudantes. Convém lembrar que o II Seminário sobre Técnicas de Controle de Raiva ${ }^{10}$ propos que as ações educativas devem ser intensificadas em estabelecimentos escolares, de todos os níveis, desenvolvendo-se atividades, na classe e extra-classe, sobre temas relacionados ao controle da Raiva. Outro dado significativo levantado por esta Tabela é que $15 \%$ dos clientes dedicam-se ao serviço doméstico, sendo a maioria $(11,7 \%)$ donas de casa. 
RAMOS, M. C. D. Perfil psicossocial das pessoas agredidas por animals raivosos ou suspeitos de ravra na Grande São Paulo. Rer. Saúde públ, S. Paulo. 12:26-34, 1978.

Somando-se os $11,7 \%$ de donas de casa com us $26,4 c_{r}$ dos pacientes com menos de 13 anos que não têm ocupação tem-se $38,1 \%$ de clientes, os quais pöe em evidência a necessidade de se planejar uma programação que atinja às familias, através de "lideres e grupos da comunidade local, aprovadas pelos veículos de comunicação de massa." "n
Quanto à faixa etária produtiva, destacam-se os trabalhadores do comércio e serviços $(13 \%)$ e os da indústria $(10,2 \%)$ que poderão ser alvo de programações em etapas posteriores.

Ainda sobre ns programas de educação sanitária deve-se destacar que eles devem ser desenvolvidos de maneira contínua e não apenas durante as campanhas ${ }^{10}$.

TA B E L A 5

Clientela atendiaa pelo Serviço Social do Instituto Pasteur, segundo a ocupação.

\begin{tabular}{|c|c|c|c|}
\hline Ocupação & & $n^{\circ}$ & $\%$ \\
\hline Sem ocupação & $\begin{array}{l}\text { menos de } 13 \text { anos } \\
\text { desempregado, aposentado e doente. }\end{array}$ & $\begin{array}{r}311 \\
42\end{array}$ & $\begin{array}{r}26,4 \\
3,6\end{array}$ \\
\hline Escolar & $\begin{array}{l}\text { estudante } \\
\text { professor }\end{array}$ & $\begin{array}{r}300 \\
08\end{array}$ & $\begin{array}{r}25,4 \\
0,7\end{array}$ \\
\hline Serviço doméstico & $\begin{array}{l}\text { prendas domésticas } \\
\text { empregadas doméstica }\end{array}$ & $\begin{array}{r}138 \\
31\end{array}$ & $\begin{array}{r}11,7 \\
3,3\end{array}$ \\
\hline $\begin{array}{l}\text { Comércio e } \\
\text { Serviços }\end{array}$ & $\begin{array}{l}\text { não qualificado } \\
\text { qualificado } \\
\text { proprietário comercial } \\
\text { profissional liberal }\end{array}$ & $\begin{array}{l}86 \\
43 \\
12 \\
13\end{array}$ & $\begin{array}{l}7,2 \\
3,6 \\
1,1 \\
1,1\end{array}$ \\
\hline Indústria & $\begin{array}{l}\text { não qualificado } \\
\text { qualificado } \\
\text { funcionário escritório } \\
\text { proprietário }\end{array}$ & $\begin{array}{l}81 \\
35 \\
04 \\
01\end{array}$ & $\begin{array}{l}6,8 \\
2,9 \\
0,4 \\
0,1\end{array}$ \\
\hline $\begin{array}{l}\text { Construçãn } \\
\text { Civil }\end{array}$ & $\begin{array}{l}\text { servente } \\
\text { semi-qualificado } \\
\text { qualificado }\end{array}$ & $\begin{array}{l}11 \\
19 \\
08\end{array}$ & $\begin{array}{l}0,9 \\
1,6 \\
0,3\end{array}$ \\
\hline $\begin{array}{l}\text { Outros } \\
\text { Serviços }\end{array}$ & $\begin{array}{l}\text { motorista autónomo } \\
\text { ambulante } \\
\text { polícia militar } \\
\text { pastor }\end{array}$ & $\begin{array}{l}08 \\
05 \\
04 \\
01\end{array}$ & $\begin{array}{l}0,7 \\
0,4 \\
0,3 \\
0,1\end{array}$ \\
\hline Agricultura & $\begin{array}{l}\text { lavrador } \\
\text { oleiro } \\
\text { jardineiro } \\
\text { fazendeiro }\end{array}$ & $\begin{array}{l}07 \\
02 \\
02 \\
02\end{array}$ & $\begin{array}{l}0,8 \\
0,2 \\
0,2 \\
0,2\end{array}$ \\
\hline Total & & 1.177 & 100,0 \\
\hline
\end{tabular}

Quanto à habitação, a Tabela 6 mostra que $48,2 \%$ das residências da clientela contam com cerca de arame ou madeira, ou são totalmente desprotegidas, o que favorece a agressão de animais contaminados no próprio domicílio. Este dado mostra também a precariedade das condições habitacionais de uma significativa percentagem da população atingida por animais raivosos ou suspeitos. 
RAMOS, M. C. D. Perfil psicossocial das pessozs agredidas por animais raivnsos ou suspeitos de raiva na Grande São Paulo. Rer. Sande publ., S. Paulo, 12:26-34, 1978.

T'A EEI, A t

Clientela atendida pelo Serviço Social do Instituto Pasteur. segundo o tipo de protecão habitacional.

\begin{tabular}{|c|c|c|c|c|}
\hline Habitação & & & Ne & $\%$ \\
\hline Com proteção & $\begin{array}{l}\text { apartamento } \\
\text { pensão. hotel. casa }\end{array}$ & $\begin{array}{l}\text { com muro de } \\
\text { alvenaria }\end{array}$ & $\begin{array}{r}47 \\
05 \\
558\end{array}$ & $\begin{array}{r}3.9 \\
0.4 \\
47.5\end{array}$ \\
\hline Sub-total & & & 610 & 51.8 \\
\hline \multirow{3}{*}{$\begin{array}{c}\text { Com proteção } \\
\text { Parcial } \\
\text { ou } \\
\text { Sem protecão }\end{array}$} & casa de alvenaria & $\begin{array}{l}\text { com cerca de } \\
\text { madeira ou arame. } \\
\text { sem proteção }\end{array}$ & $\begin{array}{l}238 \\
187\end{array}$ & $\begin{array}{l}19.8 \\
16.1\end{array}$ \\
\hline & casa de madeira & $\begin{array}{l}\text { com cerca de } \\
\text { madeira ou arame } \\
\text { sem proteção } \\
\text { alojamento de } \\
\text { emprego }\end{array}$ & $\begin{array}{l}72 \\
64\end{array}$ & $\begin{array}{l}6.1 \\
5.4 \\
0.6\end{array}$ \\
\hline & $\begin{array}{l}\text { casa de barro } \\
\rightarrow \text { patha. }\end{array}$ & $\begin{array}{l}\text { com cerca de } \\
\text { madeira }\end{array}$ & & 0.2 \\
\hline Sub-total & & & 567 & 48.2 \\
\hline Total & & & 1.177 & 100,0 \\
\hline
\end{tabular}

A Tabela 7 destaca que $66,5 \%$ da clientela procede da Capital de São Paulo, do.s quais uma grande parcela $(40,5 \%)$ vem da zona suburbana. Dos $21,5 \%$ procedentes dos municipios da Grande São Paulo, $15 \%$ também provêm da periferia. No total, portanto, são $62,2 \%$ procedentes das zonas suburbanas de suas cidades. Tais percentagens salientam a importància de se planejar programas que atinjam prioritariamente a população das periferias de São Paulo e dos municipios limitrofes. Deve-se destacar, também, que a maioria da clientela atendida pelo Instituto Pasteur procede de uma região sabidamente pobre e precariamente servida por infra-estrutura.

A Tabela 8 demonstra que $79,6 \%$ da clientela é de nivel sócio-econômico baixo, cuja renda per capita varia entre Cr\$130,00 a menos de Cr\$2.000,00 mensais. Destes, convém destacar que $34,9 \%$ vivem en condições sub-humanas, uma vez que a renda per capita mensal é inferior a $\operatorname{Cr} \$ 500,00$. Os restantes, $20,4 \%$ que procuram o Instituto Pasteur, pertencem à classe média. Portanto, os programas preventivos anti-rábicos devem levar basicamente em consideração a população de nivel sócio-econômirn baixo. O II Seminário sobre Técnicas de Controle da Raiva ${ }^{10}$ já recomendara que as ações educativas devem ser programadas a nível local, levando-se em conta os padrões sócio-econômico-culturais da população. nutro dado constatado nessa Tabela é n grande numero de familias com 5 a 6 membros $(33.5 \%)$ e com 3 a 4 membros $(29,9 \%)$. 
ramos, M. C. D. Perfil psicossocial das pessoas agredidas por animais rairosos ou suspeitos de lalva na Grande São Paulo. Reve. Saride públ, S. Puulo, 12:26-14, 1978.

TA $B$ E I A 7

Clifntela atendida pelo Serviço Social do Instituto Pasteur, segundo a procedência $e$ a zona da cidade onde reside.

\begin{tabular}{|c|c|c|c|c|}
\hline Procedência & $\begin{array}{l}N \% \\
(\%)\end{array}$ & $\begin{array}{c}N^{\circ} \\
(\%)\end{array}$ & $\begin{array}{c}\text { Rural } \\
\begin{array}{c}\text { No } \\
(\%)\end{array}\end{array}$ & Total \\
\hline Capital & $\begin{array}{l}305 \\
(25,9)\end{array}$ & $\begin{array}{l}477 \\
(40.5)\end{array}$ & $\left(\begin{array}{l}1 \\
(\quad 0,1)\end{array}\right.$ & $\begin{array}{c}783 \\
(\quad 66,5)\end{array}$ \\
\hline $\begin{array}{l}\text { Município da Grande } \\
\text { São Paulo }\end{array}$ & $\begin{array}{l}48 \\
(\quad 4.0)\end{array}$ & $\begin{array}{l}177 \\
(15.0)\end{array}$ & $\stackrel{28}{(\quad 2,5)}$ & $\begin{array}{c}253 \\
(\quad 21,5)\end{array}$ \\
\hline Interior & $\begin{array}{l}36 \\
(\quad 3.1)\end{array}$ & $\begin{array}{l}77 \\
(\quad 6.5)\end{array}$ & $\begin{array}{l}20 \\
(\quad 1,7)\end{array}$ & $\begin{array}{c}133 \\
(\quad 11.9)\end{array}$ \\
\hline Outros Estados & $\begin{array}{ll} & 5 \\
(\quad 0.4)\end{array}$ & $\begin{array}{l}2 \\
(\quad 0.2)\end{array}$ & - & $\begin{array}{l}7 \\
(\quad 0.6)\end{array}$ \\
\hline Sem endereço fixo & $\begin{array}{l}1 \\
(0.1)\end{array}$ & - & $\overline{-}$ & $\begin{array}{l}1 \\
0,1)\end{array}$ \\
\hline Total & $\begin{array}{l}359 \\
(33,7)\end{array}$ & $\begin{array}{l}73.3 \\
(62,2)\end{array}$ & $\begin{array}{l}49 \\
(\quad 4.1)\end{array}$ & $\begin{array}{l}1.177 \\
(100,0)\end{array}$ \\
\hline
\end{tabular}

Quanto às condições emocionais dos atingidos por animais raivosos ou suspeitos, $63,1 \%$ vêm às entrevistas sem ansiedade. Constatou-se, também, que $64,9 \%$ desconhecem os reais riscos da toença; destes, 50,3\% mantiveram-se calmos, podendo talvez significar que a ausência de ansiedade seja decorrente do insuficiente grau de conhecimento sobre a doença.

A maioria da clientela $(84,8 \%)$ tem nível de compreensão que varia entre bom $(20,3 \%)$ e regular $(64,5 \%)$, sendo, portanto, passiveis de orientação; destes, $45,7 \%$ tem grande conhecimento insuficiente sobre a doença (Tabela 10). Conseqüentemente, não podem avaliar a importância do tratamento médico prescrito. Esta tem sido uma das causas mais significativas do abandono do tratamento anti-rábico.

\section{CONCLUSOES}

Os resultados desta investigação permitem concluir :
1) A clientela típica do Instituto Pasteur se caracteriza psicossocialmente por:

- Ser do sexo masculino, solteiro, na faixa etária entre 0 a 20 anos, com predominância de 0 a 13 anos; não ter ocupação, ou ser estudante, ou ainda dedicar-se ao serviço doméstico, principalmente como dona de casa. Proceder da periferia da Capital ou da dos municipios limitrofes; ser de nível sócio-econômico baixo, sendo que uma significativa percentagem vive em condições sub-humanas; uma parcela considerável corre o risco de se contaminar en sua própria residência, uma vez que a mesma não conta com proteção; desconhecer os reais riscos da doença, mas ser seu nivel de compreensão passível de ações educativas.

2) Os programas educativos de caráter continuo e as campanhas devem: 


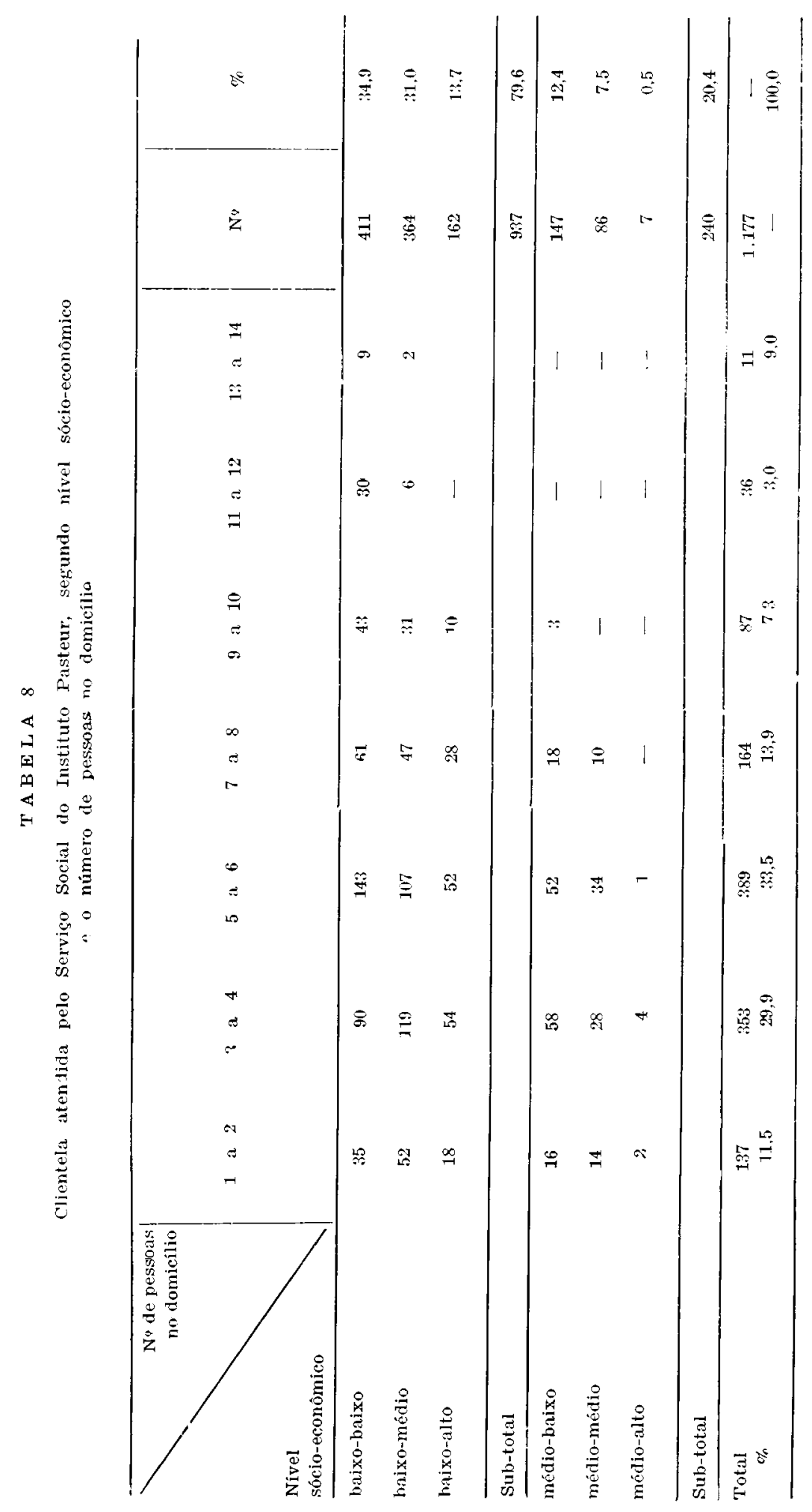


RAMOS, M. C. D. Perfil psicossocial das pessoas agredidas por animais raivosos ou suspeitos de raiva na Grande São Paulo. Rev. Saúde públ., S. Paulo, 12:26-34, 1978.

\section{TA B E L A}

Relação entre condições emocionais e grau de conhecimento sobre a doença da clientela atendida pelo Serviço Social do Instituto Pasteur.

\begin{tabular}{|c|c|c|c|}
\hline $\begin{array}{l}\text { condições } \\
\text { emocio- } \\
\text { nais }\end{array}$ & Sem ansiedade & Som ansiedade & $\begin{array}{l}\text { Total } \\
(\%)\end{array}$ \\
\hline Insuficiente & $\begin{array}{l}593 \\
(50,3)\end{array}$ & $\begin{array}{l}172 \\
(14,6)\end{array}$ & $\begin{array}{l}765 \\
(64,9)\end{array}$ \\
\hline Regular & $\begin{array}{l}106 \\
(9,0)\end{array}$ & $\begin{array}{l}191 \\
(16.2)\end{array}$ & $\begin{array}{l}297 \\
(25,2)\end{array}$ \\
\hline Bom & $\begin{array}{l}44 \\
(4,5)\end{array}$ & $\begin{array}{l}71 \\
(5,4)\end{array}$ & $\begin{array}{l}115 \\
(9,9)\end{array}$ \\
\hline $\begin{array}{l}\text { Total } \\
(\%)\end{array}$ & $\begin{array}{l}743 \\
(63,1)\end{array}$ & $\begin{array}{l}434 \\
(36,9)\end{array}$ & $\begin{array}{r}1.177 \\
(100,0)\end{array}$ \\
\hline
\end{tabular}

T A B E L A 10

Relação entre nível de compreensão e grau de conhecimento sobre a doença da clientela atendida pelo Serviço Social do Instituto Pasteur.

\begin{tabular}{|c|c|c|c|c|c|}
\hline $\begin{array}{l}\text { Grau de conhe- } \\
\text { cimento sobre } \\
\text { a doenca }\end{array}$ & $\begin{array}{r}\text { Nível de } \\
\text { compreen- } \\
\text { são }\end{array}$ & $\begin{array}{l}\text { No } \\
(\%)\end{array}$ & $\begin{array}{l}\text { No } \\
(\%)\end{array}$ & $\begin{array}{c}\text { No } \\
(\%)\end{array}$ & $\begin{array}{l}\text { Total } \\
(\%)\end{array}$ \\
\hline Insuficiente & & $\begin{array}{l}180 \\
(15,2)\end{array}$ & $\begin{array}{l}540 \\
(45,7)\end{array}$ & $\begin{array}{c}45 \\
(\quad 4,9)\end{array}$ & $\begin{array}{c}765 \\
(\quad 64,9)\end{array}$ \\
\hline Regular & & - & $\begin{array}{l}218 \\
(18,6)\end{array}$ & $\begin{array}{c}79 \\
(\quad 6.6)\end{array}$ & $\begin{array}{c}297 \\
(\quad 25,2)\end{array}$ \\
\hline Bom & & - & $\left(\begin{array}{l}12 \\
(1,1)\end{array}\right.$ & $\begin{array}{l}103 \\
(\quad 8,8)\end{array}$ & $\begin{array}{c}115 \\
(\quad 9,9)\end{array}$ \\
\hline Total & & $\begin{array}{l}180 \\
(15,2)\end{array}$ & $\begin{array}{l}770 \\
(64,5)\end{array}$ & $\begin{array}{l}227 \\
(20,3)\end{array}$ & $\begin{array}{l}1.177 \\
(100,0)\end{array}$ \\
\hline
\end{tabular}


RAMOS. M. C. D. Perfil psicossocial das pessoas agredidas por animais rairosos ou suspeitos

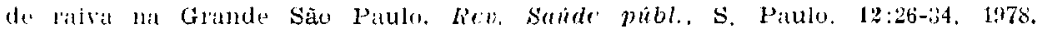

- dar prioridade absoluta às populaçoes periféricas, de nivel sócio-econòmico precário:

- levar em conta o grupo familiar, não somente o escolar, neste sentido, envolver as lideranças comunitárias e as Instituições que atinjam o citado grupo:

- dar ênfase à utilização clos meios de (omunicação que favorecam o real conlecimento dos riscos da doença e das medidas profiláticas correspondentes.

\section{AGRADECIMENTOS}

Ao Dr. Murillo Pacca de Azevedo, Dolores A. Yoda, Maria Aparecida S. Alves e Tereza Kleiman pelo estímulo prestado, sem () qual não seria possivel a execução deste trabalho.

RSPUB9/391

Ramos, M. C. D. /A psyco-sacial profile of the population exposed to the rabies virus in the cuty of $S$. Paulo and neighborhood.] Rev. Saúde públ., S. Paulo, $12: 26-34,1978$

ABSTRACT: A statistical analysis was made on the psycho-social characteristic of people attended at the Instituto Pasteur, S. Paulo, Brazil. It was concluded that the population exposed to rabies virus in the area enclosed by the Instituto comes from the suburbs of $S$. Paulo and from the surrounding cities; a considerable part is at risk of acquiring the disease at home; they ignore the real risks of the disease and so they turn up at the Instifuto showing no apprehension whatsoever. This population is susceptible of receiving education regarding rabies.

UnITERms: Rabies, psycho-social characteristics. Rabies, S. Paulo, Brazil. Health education.

\section{REFERENCIAS BIBLIOGRAFICAS}

1. ANDRADE, P. V. de. Aspectos da profilaxia da raiva no Estado de São Paulo. Arq. Hig., S. Paulo. 26:217-8. 1961.

2. ANDRADE, P. V. de \& AGUIAR, A. A. Sôro-neutralização em vacinados do Instituto Pasteur de São Paulo, Rev. Ass. med. bras., 15:451-6, 1969

3. ANDRADE, P. V. de et al. Estudo crítico da vacinação anti-rábica, nas mordeduras altas, na clientela do Instituto Pasteur de São Paulo, Arq. Hig., $\mathrm{S}$. Paulo, 29:185-7, 1964.

4. LOPEZ. M. et al. Human rabies. I. Intesive treatment. Rev. Inst. Med. trop. S. Paulo, 17:108-10, 1975.

5. MACHADO, C. G. et al. Raiva na infância Pediat, prat., $\mathbf{3 9 : 4 1 7 - 2 2 , 1 9 6 8 .}$

6. PROGRAMA de profilaxia da raiva humana no Brasil. Bol. epidem., Rio de Janeiro, 8 (24). 1976.

7. RIBEIRO NETO, A. \& MACHADO, C. G. Alguns aspectos epidemiológicos da exposição humana ao rissco da infecção pelo virus da raiva na cidade de São Paulo. Rev. Irist. Med. trop. S. Panlo, $12: 16-30,1970$.

8. SCHMID, A. W. Estudos sobre a mortalidade por várias causas no município de São Paulo. 1. Raiva, Rev. Inst. Med. trop. S. Paulo, 1:3-10, 1959.

9. SEMINARIO SOBRE TECNICAS DE CONTROLE DA RAIVA, 19, São Paulo. 1972. Recomendaģ̃es. Såo Paulo. Instituto de Saúde, 1973.

10. SEMINARIO SOBRE TECNICAS DE CONTROLE DA RAIVA, 2\%, São Bernardo do Campo, SP, 1976. Recomendações. Sảo Paulo, Centro de Controle de Zoonoses, 1976.

11. TIRIBA, A. da C. et al. Raiva humana: aspectos médicos e sociais. Análise de 141 doentes internados no hospital Emillio Ribas de São Paulo (decênio 1962 - 1971) Rev. Ass. med. bras. $18: 489-94,1972$.

Recebido para publicação em 04/07/197\% Aprovado para publicação em 5/08/197i 